poníveis, as relações com os clientes possivelmente sejam prejudicadas e até mesmo alguns deles sejam perdidos.

As previsões de vendas tornaram-se, indubitavel-

1. Introdução;

2. Modelo de análise de decisão;

3. Valor da informação adicional;

4. Informação adicional e seu custo;

5. Análise de sensibilidade;

6. Teoria bayesiana de decisão;

7. Comentários finais.

\section{Como reduzir a incerteza em previsão de vendas}

Jorge Motta

Professor titular na EAESP/FGV.

\section{INTRODUÇÃO}

A previsão de vendas e de outros resultados, como preços, custos, lucros líquidos e participação de mercado, constitui uma das pedras angulares do planejamento na administração mercadológica. Muitas decisões importantes baseiam-se em estimativas de vendas: planejamento da produção, compras de matérias-primas, despesas de propaganda e promoção de vendas, gastos com equipes de vendas, até mesmo investimentos em bens de produção como maquinaria e equipamentos.

A exatidão da previsão de vendas é uma responsabilidade indeclinável do administrador de marketing. Se ocorrer uma previsão de vendas demasiado elevada, poderá sobrevir grande acumulação de estoques, despesas de todos os tipos quiçá escapem ao controle da administração e provavelmente haverá equipamento ocioso na área de produção. Por outro lado, se acontecer uma previsão de vendas excessivamente baixa (isto é, conservadora), a firma naturalmente não conseguirá atender à procura, porque um volume adequado de produtos não será plausivelmente fabricado, vendedores treinados em número suficiente talvez não estejam dis- mente, dados de entrada críticos para uma ampla variedade de processos de tomada de decisão na administração de empresas. Com fundamento em discussões mantidas com empresários e dirigentes em projetos de consultoria, e principalmente através de nossos contatos amiudados com diretores e administradores de firmas que freqüentam os cursos oferecidos pelo Programa de Educação Continuada para Executivos (Pece) da Escola de Administração de Empresas de São Paulo, da Fundação Getulio Vargas, tornou-se evidente que muitas pessoas estão empenhadas em aperfeiçoar as técnicas profissionais que utilizam para lidar com previsões incertas.

As pressões que os custos empresariais ascendentes exercem sobre os administradores brasileiros, nestes anos recentes de agudo processo inflacionário, formam a base de uma realidade cada vez mais crítica. Lamentavelmente, pouco tem sido realizado em termos de uma abordagem estrutürada voltada ao objetivo de ajudar o administrador a estimar o valor de uma previsão relacionada com sua situação particular de tomada de decisão. A maior parte do que tem sido publicado sobre os custos de previsão refere-se às despesas decorrentes da precisão das diferentes técnicas, ou aos custos fixos e variáveis de uma operação de previsão.

A teoria de decisão, ordinária da pesquisa operacional, constitui uma técnica largamente utilizada na administração empresarial para sugerir estratégias ótimas para o tomador de decisão. Por sua vez, contém alguns elementos úteis para o executivo responsável pela elaboração de previsões. Dentre esses, destacam-se o conceito do valor esperado de uma variável aleatória (esperança matemática) e a teoria bayesiana de decisão.

As técnicas de análise de decisão têm sido recentemente aplicadas à escolha de estratégias alternativas por algumas empresas que operam no mercado brasileiro. Estes métodos facultam ao administrador programar uma estratégia como uma série de decisões seqüenciadas com reconhecimento explícito da incerteza em cada passo. Uma aplicação nova da análise de decisão é dada pela estimativa de vendas de produtos novos, que assiduamente mesclam altos níveis de incerteza com extensas diferenças em lucro incremental.

A abordagem da análise de decisão abrange, normalmente, estas quatro etapas: 1

1. Estruturação do problema. Este passo envolve definição dos objetivos gerais da empresa, determinação de medidas de eficácia, identificação das restrições existentes sobre as ações e caracterização do problema em termos cronológicos. Inclui, também, descrição de cursos de ação alternativos.

2. Atribuição de probabilidade aos resultados possíveis. A plausibilidade de ocorrência de diversos resultados, dependentes das ações gerenciais, deve ser medida. Esta avaliação pode ser puramente subjetiva ou 
talvez inclua uma análise do sistema de comportamento passado (aferição objetiva).

3. Ajustamento de valores monetários ou utilidades às conseqüências. As preferências do tomador de decisão devem ser fixadas em valores monetários ou em termos de utilidades. ${ }^{2}$

4. Análise do problema. Identifica-se o melhor curso de ação por um procedimento fundado no cômputo da média dos resultados terminais e no sentido inverso em que eles foram estabelecidos. Apresentaremos mais adiante alguns exemplos para ilustrar o método básico.

Usaremos a experiência de dois fabricantes de porte médio para demonstrar a seleção de estratégias ótimas, dada a existência de substancial incerteza previsional. Para facilitar a exposição, arredondaram-se os valores monetários. Como geralmente sucede na prática, o comportamento racional descrito nos dois exemplos apoiou-se num sistema de informações incerto. Recorreu-se à inferência bayesiana como um processo apropriado para lidar com este tipo de problema. O teorema ou regra de Bayes é um instrumento essencial ao processo de tomar decisões em clima de elevada incerteza (ver anexo 1). Embora os modelos teóricos de decisão sob incerteza sejam complexos, cremos que qualquer administrador profissional possa aplicar o sistema especial aqui elaborado.

Após a Introdução, o item 2 descreve um modelo simples de análise de decisão. A situação ilustrada diz respeito a um evento previsional, não obstante ser possível usar esse esquema em qualquer seleção passo-a-passo de alternativas, seja qual for o problema analisado em ambiente de incerteza. $O$ terceiro item estima o custo da incerteza e o valor da informação adicional. A seguir, no item 4, mostra-se como uma decisão foi tomada com relação à conveniência de investir dinheiro na aquisição de informação de predição complementar. Posteriormente, no item 5, expõe-se como a análise de sensibilidade pode ajudar a limitar as conseqüências de medidas incertas. $O$ penúltimo item apresenta o mesmo modelo de análise de decisão aplicado à resolução de um problema mais complexo, numa situação de incerteza configurada em diversos estágios. Finalmente, no item 7 , integram-se as técnicas dissertadas num sistema de processamento de informações para resolução racional de problemas com base em previsões incertas.

\section{MODELO DE ANÁLISE DE DECIS $\tilde{A} O$}

Um diagrama de fluxo do processo decisório pode ser representado pelo esquema da figura 1, que identifica duas classes de alternativas como conjuntos de ramos: "aumentar" ou "não aumentar" as instalações atuais de produção para fabricar um produto novo.

O primeiro tipo de ramo da figura 1 mostra o conjunto de decisões sob controle parcial do administrador marketing. São ações alternativas disponíveis com recursos parcialmente sob seu comando, identificadas com um quadrado desenhado na origem do ramo. A segunda categoria de ramo constitui o conjunto de resul-
Figura 1

Diagrama de decisão representando uma situação de análise prévia

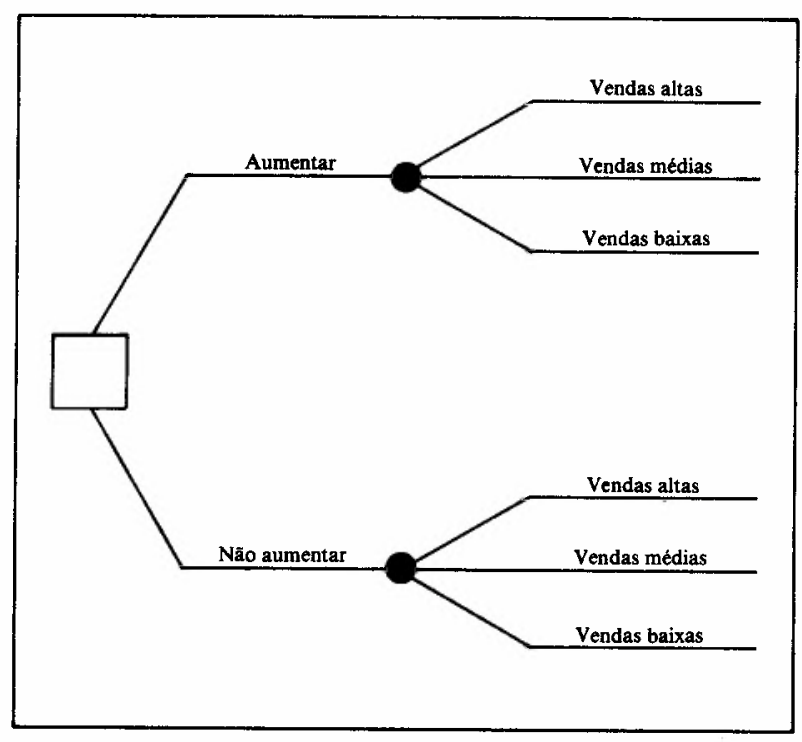

tados incertos de alguns eventos que fogem ao controle imediato do administrador. Destacam-se por uma circunferência colocada na origem do ramo.

Embora esta decisão, assinalada com um quadrado na origem, esteja sob o controle parcial do administrador de marketing, sua lucratividade dependerá do nível das vendas futuras. Como o produto é novo, existe muita incerteza com relação às vendas estimadas, e o administrador defronta-se com vários montantes possiveis de vendas. A figura 1 mostra três níveis, com uma circunferência à esquerda dos ramos, porém é claro que a variedade de estimativas de vendas poderia ser superior a três. Pressupõe-se, por outro lado, que as políticas de produto, distribuição e promoção tenham sido determinadas. Por conseguinte, o volume real de vendas é, no momento, uma condição ambiental incerta.

É importante ressaltar que a seqüência de decisões e eventos foi organizada em ordem natural da esquerda para a direita. Na figura 1 , deve-se tomar uma decisão entre as alternativas de expansão. Se a opção for "aumentar", o montante real de vendas identificado à direita é um elemento crítico do lucro. Se a escolha for "não aumentar", poder-se-á manter apenas um nível mínimo de vendas, e a procura variável das vendas não-realizadas terá um impacto significativo sobre os lucros perdidos.

Apesar de a ordem de decisão e conseqüências deslocar-se da esquerda para a direita, a mensuração dos resultados, computados a seguir e indicados na figura 2 , procede da direita para a esquerda. O conjunto final de combinações individuais de resultados aparece na extrema direita. $O$ processo de avaliação começa com esses valores e move-se para a esquerda numa seqüência de combinação de quantias.

O lucro ou prejuízo marginal, decorrente de cada ramo de resultados, aparece à direita desse ramo, conforme mostra a figura 2 . Se as atuais instalações produtivas forem ampliadas, as vendas altas ou médias se- 
rão lucrativas, porém um baixo volume de procura redundaria num prejuízo de Cr\$1 bilhão. Por outro lado, se a fábrica não for aumentada, um volume baixo de vendas, que é o único nível de procura que poderá ser atendido, acarretará um lucro incremental de Cr\$600 milhões.

\section{Figura 2}

Diagrama de árvore de decisão mostrando valores em situação de análise prévia (Montantes expresso em Cr $\$ 1$ milhão)

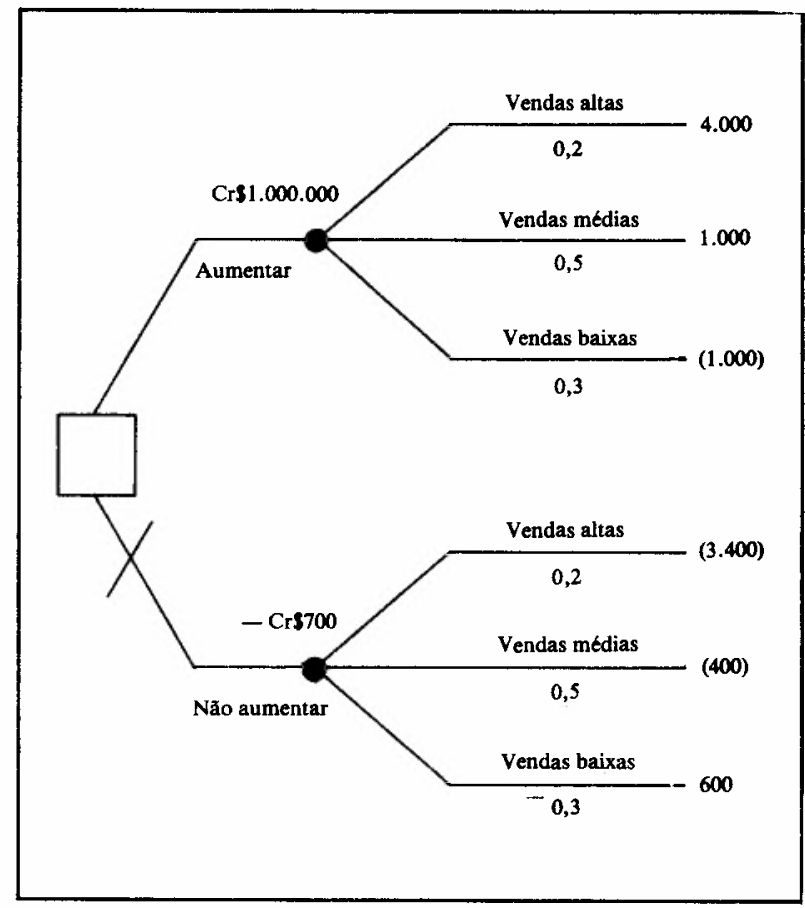

Para avaliar a lucratividade das estratégias alternativas, o tomador de decisão deve de algum modo resumir os diversos níveis possíveis de vendas numa quantia única e representativa. Valores relativos a probabilidades podem ser usados para aferir a incerteza entre essas alternativas e, para tanto, basta que ele atribua percentagens aleatórias a cada uma das estimativas de vendas. Na figura 2, essas frações são $20 \%$ para vendas altas, $50 \%$ para médias e $30 \%$ para baixas. Uma cifra única, que represente a lucratividade "esperada" das estimativas de vendas incertas, pode ser calculada em termos da média das lucratividades dos três níveis de procura, cada montante sendo ponderado por sua respectiva plausibilidade. Desta maneira, pode-se chegar a estes resultados com base na figura 2:

$0,2(\operatorname{Cr} \$ 4.000)+0,5(\operatorname{Cr} \$ 1.000)+0,3(-\operatorname{Cr} \$ 1.000)=$ Cr $\$ 1.000$

e $0,2(-\operatorname{Cr} \$ 3.400)+0,5(-\operatorname{Cr} \$ 400)+0,3(\mathrm{Cr} \$ 600)=$ $-\mathrm{Cr} \$ 700$

Salientam-se na figura 2 algumas informações importantes:

1. São três os eventos incertos e relevantes: $E_{1}$ (as vendas do novo produto são altas), $E_{2}$ (as vendas são médias) e $E_{3}$ (as vendas são baixas).
2. As ações ou estratégias disponíveis são duas: $\mathbf{A}_{1}$ (ampliar as instalações produtivas da firma) e $\mathrm{A}_{2}$ (não ampliar essas instalações.

3. Tanto os eventos incertos como as ações cogitadas são mutuamente excludentes e coletivamente exaustivos.

4. Os rendimentos $(\mathrm{Cr} \$ 4.000, \mathrm{Cr} \$ 1.000 \mathrm{e}-\mathrm{Cr} \$ 1.000)$, associados à estratégia $\mathrm{A}_{1}$, representam os valores assumidos por uma variável aleatória, ou seja, uma função de variável real, cujo domínio é o conjunto de eventos $E_{i}$, que faz corresponder a cada evento um número real.

5. Os rendimentos (-Cr $\$ 3.400,-\mathrm{Cr} \$ 400$ e $\mathrm{Cr} \$ 600)$, vinculados à estratégia $A_{2}$, significam que, se as instalações produtivas não forem ampliadas, a empresa abrirá mão de lucros equivalentes a $\mathrm{Cr} \$ 3.400 \mathrm{se}$ as vendas forem altas e a $\mathrm{Cr} \$ 400$ se as vendas forem médias. Se as vendas forem baixas, todavia, os lucros incrementais serão de Cr $\$ 600$.

No caso do problema retratado pela figura 2 , o tomador de decisão não deverá levar em conta o fato de que as atuais instalações fabris da companhia poderão gerar lucros adicionais consideráveis durante o período de planejamento. Como lembram Alderson e Green, normalmente $o$ administrador estaria interessado apenas nos lucros que poderiam variar em conseqüência dos planos que estão sendo avaliados. ${ }^{3}$ Com base na informação disponível no momento, a decisão ótima seria “aumentar" (cujo valor monetário esperado é um lucro incremental de Cr\$1.000), em vez de "não aumentar" (cujo valor monetário esperado é uma perda de oportunidade equivalente a $\mathrm{Cr} \$ 700)$. Corta-se a estratégia rejeitada com uma barra transversal, para significar que a estratégia alternativa é a decisão ótima do administrador.

De que maneira o tomador de decisão atribui probabilidade ou chances a resultados de vendas incertos? Aceita-se que o administrador lance mão de todas as informações disponíveis, baseadas em análise das vendas passadas, e ajuste coeficientes aleatórios à ocorrência dos diversos eventos, com fundamento em pontos de vista pessoais. Segundo este conceito, mede-se a probabilidade de um evento pelo grau de crença ou confiança conferido por determinado indivíduo ao sucesso de um evento, com base na evidência acessivel. Estas informações podem incluir dados sobre a freqüência relativa de ocorrência e quaisquer outros informes de natureza quantitativa ou não. Se a pessoa acreditar que é improvável que aconteça certo evento, seguramente estabelecerá uma probabilidade próxima de zero para sua ocorrência. Se julgar que é muito provável que o evento aconteça, sua inclinação será a de fixar uma probabilidade vizinha de um. ${ }^{4}$

Ả primeira vista, este método poderá parecer extremamente descuidado, porém os itens seguintes deste artigo irão demonstrar que uma decisão individual é meramente uma peça de um processo de melhoria progressiva. Probabilidades fundadas em ignorância completa podem até mesmo caracterizar a decisão inicial (como veremos no próximo item). 
Figura 3

Análise de decisăo com disponibilidade de informaç đa de previsão

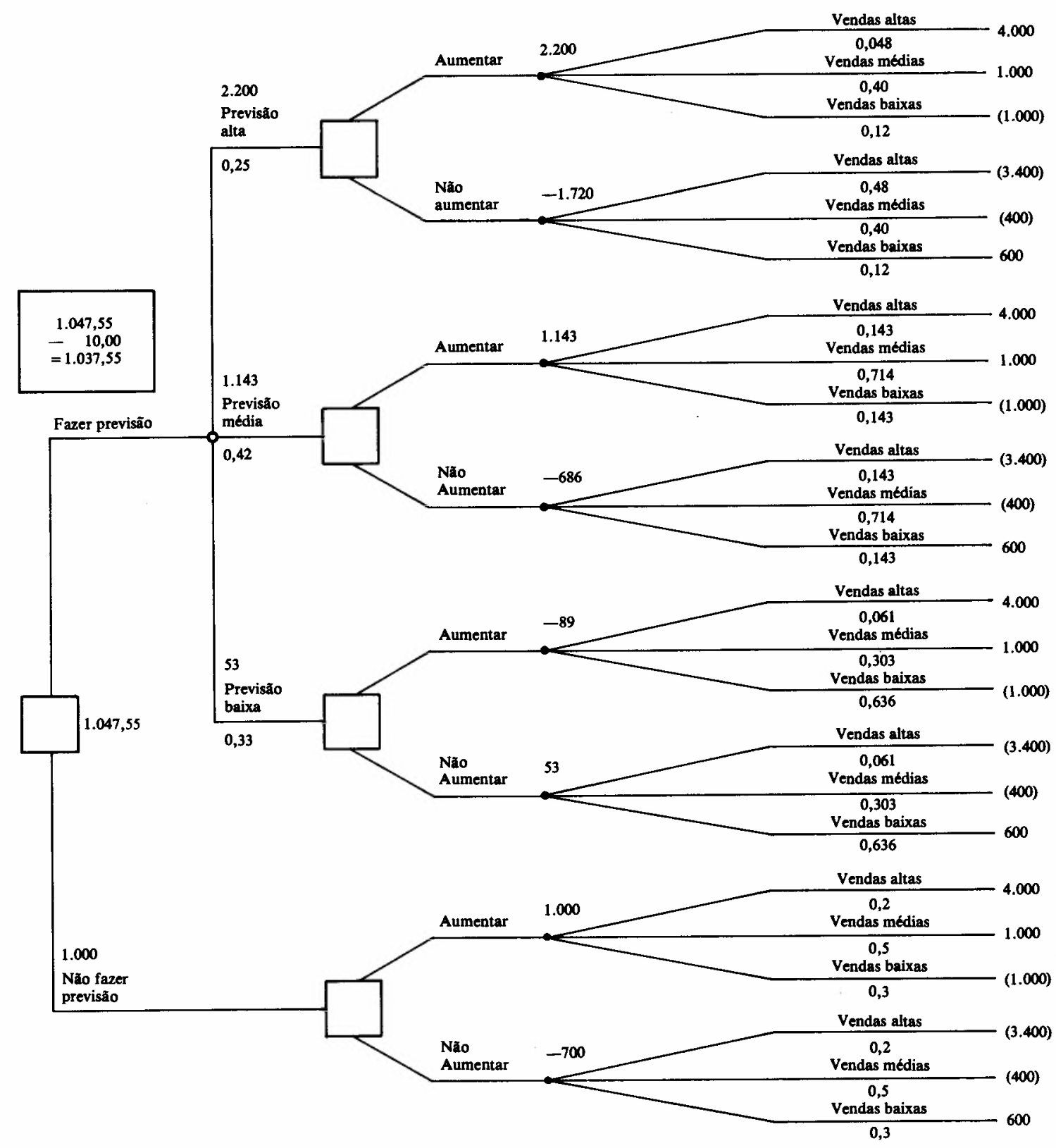

3. VALOR DA INFORMAÇAO ADICIONAL

Tomemos a decisão prévia de ampliar as atuais instalações produtivas da empresa como ponto de partida. Como se determina se açōes estratégicas posteriores seriam lucrativas? Uma das alternativas envolveria a coleta de informação adicional sobre o nível de procura do novo produto, ou tentar reduzir o grau de incerteza que cer- ca a estimativa de vendas. Tais esforços acarretam dispêndios, todavia. Compete ao tomador de decisão, portanto, comparar o valor monetário associado à redução da incerteza com o custo de obtenção da informação incremental.

A inferência bayesiana faculta ao tomador de decisão melhorar seu conhecimento sobre determinado nivel de probabilidade, mediante a colheita de novas informações. O melhor lugar para iniciar um processo de 
aperfeiçoamento da decisão consiste na aferição de quanto se poderia aumentar o lucro marginal pela eliminação da incerteza. Posto não seja possível conseguir informação absolutamente certa, o valor esperado da informação perfeita (abreviado pela sigla VEIP) merece ser computado como um limite superior à quantia que o administrador estaria disposto a pagar por informação complementar.

Existem dois métodos de cálculo do valor esperado da informação perfeita. São os seguintes:

1. Calcular a diferença entre o lucro marginal decorrente de uma decisão ótima, baseada na posse de informação perfeita, e a decisão prévia original de "aumentar" as instalações da fábrica sem conhecimento das vendas reais do novo produto. Esta diferença leva o nome de perda de oportunidade, ou pesar, e deve ser calculada para cada nivel de estimativa das vendas. Se o tomador de decisão soubesse de antemão que iria ocorrer o evento $E_{1}$ ("vendas altas"), sua escolha recairia sobre a alternativa de "aumentar as instalações produtivas" $\left(A_{1}\right)$, e seu lucro adicional montaria a Cr $\$ 4.000$. Se sucedesse o evento $E_{2}$ ("vendas médias"), a opção do administrador seria, também, por "aumentar as instalações fabris". Neste caso, seu ganho adicional seria de $\mathrm{Cr} \$ 1.000$. Se acontecesse o evento $\mathrm{E}_{3}$ ("vendas baixas"), a preferência do decisor seria por $\mathrm{A}_{2}$ ("não aumentar a capacidade de produção"), e seu lucro marginal seria de Cr $\$ 600$. O lucro esperado, dada a existência de informação perfeita relativa à ocorrência dos eventos incertos, seria dado pela igualdade:

$$
\begin{aligned}
& 0,2(\mathrm{Cr} \$ 4.000)+0,5(\mathrm{Cr} \$ 1.000)+0,3(\mathrm{Cr} \$ 600)= \\
& \mathrm{Cr} \$ 1.480 .
\end{aligned}
$$

Tabela 1

Determinação da perda de oportunidade ou pesar
Este valor hipotético tem o nome de Lucro Esperado com Informação Perfeita e é representado pela sigla LE/IP.

Para se estimar o valor esperado da informação perfeita, subtrai-se do Lucro Esperado com Informação Perfeita o montante relativo à decisão ótima em situação de incerteza (abreviado pelo símbolo $\mathrm{DO} / \mathrm{SI}$ ). Teremos pois:

$$
\begin{aligned}
& \text { VEIP }=\mathrm{LE} / \mathrm{IP}-\mathrm{DO} / \mathrm{SI}=\mathrm{Cr} \$ 1.480-\mathrm{Cr} \$ 1.000= \\
& \mathrm{Cr} \$ 480 .
\end{aligned}
$$

2. Estimar a perda de oportunidade esperada decorrente da escolha da ação ótima em condições de incerteza. Denomina-se perda de oportunidade o prejuízo em que se incorre por não se selecionar a melhor ação disponível. As perdas de oportunidade são calculadas separadamente para cada evento que poderia acontecer. Dado o sucesso de um evento qualquer, podemos determinar a melhor estratégia disponível. Para determinado evento, a perda de oportunidade de uma ação é representada pela diferença entre o ganho desse ato e o rendimento da melhor estratégia que poderia ter sido eleita. As probabilidades dos eventos são empregadas para computar a perda de oportunidade média ponderada para cada ação. ${ }^{5}$

Se $E_{1}$ ("vendas altas") fosse verdadeiro, a ação $A_{1}$ ("aumentar as instalações produtivas") seria ótima e, por conseguinte, o tomador de decisão não sofreria perda de oportunidade ao optar por $\mathrm{A}_{1}$. Haveria perda de oportunidade, contudo, se ele escolhesse a estratégia $\mathrm{A}_{2}$ ("'não aumentar a capacidade de produção"). Se ocorresse o evento $E_{2}$ ("vendas médias"), a opção por $A_{1}$ seria a melhor $e$, conseqüentemente, com perda de

\begin{tabular}{llllll}
\hline $\begin{array}{l}\text { Nivel de } \\
\text { vendas }\end{array}$ & $\begin{array}{l}\text { Decisão com } \\
\text { informação } \\
\text { perfeita }\end{array}$ & Ganho & $\begin{array}{c}\text { Decisão } \\
\text { prévia }\end{array}$ & Ganho & Pesar \\
\hline $\begin{array}{lllll}\text { Vendas altas } \\
\text { Vendas médias }\end{array}$ & Aumentar & Cr $\$ 4.000$ & Aumentar & Cr $\$ 4.000$ & Cr $\$ 0$ \\
Vendas baixas & Aumentar & Cr $\$ 1.000$ & Aumentar & Cr $\$ 1.000$ & Cr $\$ 0$ \\
Não aumentar & Cr $\$ 600$ & Não aumentar & - Cr $\$ 1.000$ & Cr $\$ 600$ \\
\hline
\end{tabular}

oportunidade nula. Perda de oportunidade seria suportada se a escolha recaísse em $A_{2}$. No caso do evento $E_{3}$ ("vendas baixas"), a preferência por $\mathrm{A}_{2}$ não levaria à perda de oportunidade e o contrário sucederia se a seleção favorecesse a ação $A_{1}$.

Note-se que a informação perfeita não altera o meio ambiente - isto é, todos os níveis de procura podem ainda ocorrer - , porém estamos de posse de uma regra de decisão melhorada pelo fato de termos acesso a conhecimento prévio. A tabela 1 ilustra o cômputo do pesar para cada nível de vendas. Quando as estratégias de decisão com e sem informação perfeita forem idênticas, como acontece em nosso problema com a ação "aumentar"' em situações de vendas altas e médias, o valor do pesar deve se nulo. Na hipótese de vendas baixas com informação perfeita, todavia, a decisão prévia de "aumentar" seria inferior em Cr\$1.600 à opção por "não aumentar".

Semelhantemente à decisão prévia, precisamos de uma única cifra para representar o "valor esperado" da informação perfeita. Mais uma vez, o uso de uma média ponderada pelas atribuições de probabilidades, aplicadas agora ao conjunto de pesares da tabela 1 , nos proporciona o montante desejado.

VEIP $=0,2(\mathrm{Cr} \$ 0)+0,5(\mathrm{Cr} \$ 0)+0,3(\mathrm{Cr} \$ 1.600)=$ Cr $\$ 480$.

Esta quantia representa o valor máximo esperado que poderia ser ganho em lucro incremental com acesso à informação perfeita. $O$ valor esperado da informação perfeita estabelece o limite superior do montante 
que o tomador de decisão estaria disposto a pagar por informação adicional. ${ }^{6}$

A análise prévia poderia ter início a partir de uma posição de ignorância completa sobre as probabilidades de se alcançar os três níveis de procura do novo produto. Se isto acontecesse, o tomador de decisão poderia atribuir probabilidades iguais aos eventos incertos. Logo, os valores seriam 1/3 para cada um dos niveis de vendas estimadas. Recorrendo aos métodos anteriores - apenas com alteração das plausibilidades - , a lucratividade esperada da venda incerta passaria a ser:

$(1 / 3)(\mathrm{Cr} \$ 4.000)+(1 / 3)(\mathrm{Cr} \$ 1.000)-(1 / 3)(\mathrm{Cr} \$ 1.000)$ $=\mathrm{Cr} \$ 1.333$.

O valor esperado da informação perfeita (VEIP) em situação de ignorância completa é o seguinte:

$(1 / 3)(\mathrm{Cr} \$ 0)+(1 / 3)(\mathrm{Cr} \$ 0)+(1 / 3)(\mathrm{Cr} \$ 1.600)=$ Cr $\$ 533$.

As cifras individuais dependem das probabilidades escolhidas, porém, se a quantia de $\mathrm{Cr} \$ 1.333$ substituir Cr\$1.000 na figura 2, a decisão preferida será ainda aumentar as instalações produtivas da empresa. A decisão prévia é insensível à modificação das probabilidades originais, fixadas subjetivamente, para a aceitação do critério de ignorância fundado na estipulação de plausibilidades iguais para os eventos incertos, conforme demonstramos. Em outras palavras, podemos afirmar que, pelo menos no âmbito da discussão, a atribuição específica de probabilidades não é um ponto crítico de decisão. Este é um exemplo de análise de sensibilidade, que desempenha importante papel na investigação sistemática da incerteza.

\section{INFORMAÇÃO ADICIONALE SEU CUSTO}

Fontes de informação adicional disponiveis para o tomador de decisão reduzem, normalmente, a incerteza, sem atingir a condição limitante de serem perfeitas. $O$ problema com que se defronta o administrador consiste em determinar se a incerteza menor é suficientemente valiosa para compensar o seu custo. $O$ ganho resulta da eficiência melhorada das decisões que podem ser tomadas com informações mais seguras. A figura 3 diagrama um sistema de decisão para apurar se a empresa deveria adquirir informação previsional além da que foi utilizada previamente na desisão de aumentar as instalações produtivas, conforme mostram as figuras 1 e 2 .

Um serviço de previsão de vendas pode ser comprado ao custo de $\mathrm{Cr} \$ 10$ (Cr\$10 milhões). O administrador enfrenta duas alternativas: adquirir o serviço que lhe foi oferecido, ou, simplesmente, aumentar a capacidade produtiva da fábrica, conforme foi decidido na análise prévia do problema. O nó de decisão relativo a estas alternativas aparece à esquerda na figura 3 . A opção prévia de aumentar está registrada no conjunto inferior de ramos. Esta decisão proporciona um valor esperado de Cr $\$ 1.000$ com base na estratégia de "aumentar'. O diagrama completo da figura 2 foi reproduzi- do na parte inferior da figura 3 para completar o esquema decisório, porém nessa altura do processo de tomada de decisão necessita-se, apenas, a "melhor opção" prévia.

O emprego de um serviço de previsão de vendas resulta em dois estágios de eventos: o montante real das vendas do novo produto e o nível da previsão. Qualquer um dos três valores da previsão pode ser combinado com as três cifras relativas às vendas reais, logo devem ser considerados nove ramos referentes aos resultados possíveis. Por outro lado, temos duas decisões: "aumentar" $e$ "não aumentar". Conseqüentemente, a parte superior da figura 3, que analisa todos os resultados decorrentes da escolha do "serviço de previsão de vendas", requer um total de 18 ramos.

$\mathrm{Na}$ figura 3, os resultados previsionais precedem os segmentos das vendas reais, porque os primeiros são obtidos como informação adicional antes que a procura final seja conhecida. As informações do administrador a respeito das probabilidades das consequêencias da previsão variarão com os níveis reais das vendas. As plausibilidades de que o método de previsão disponível forneça diversas previsões, dado cada nível da procura real do novo produto, são estimadas e registradas na coluna "condicional" da tabela 2 . Estes valores podem ser subjetivos, ou em deerminadas ocasiões podem ser conseguidos com base nos registros históricos do serviço previsional. Trata-se, simplesmente, de assinalar o número de vezes em que a previsão "bateu" com as vendas reais, "ficou moderadamente fora do alvo" ou representou um "malogro completo" para cada um dos três níveis de procura de vendas. Convertem-se os números de proporçōes, registrados sob a forma de frações decimais na tabela 2.

Se o serviço revisional proporcionar alguma utilidade na redução da incerteza, será necessário que estime probabilidades relativamente mais elevadas para previsões corretas do que para incorretas. Na tabela 2, observa-se que a probabilidade de previsão é 60 ou $70 \%$, enquanto que as plausibilidades de estimativas imperfeitas são de 10 ou $20 \%$, com uma única exceção, a de $30 \%$.

Como na análise prévia, a procura do novo produto, antes da coleta de informação incremental, foi estimada subjetivamente em 20,50 e $30 \%$, respectivamente, para os três níveis de vendas. A coluna de "probabilidades prévias" da tabela 2 registra esta informação sob a forma de frações decimais.

O tomador de decisão estimou: 1 . as probabilıdades de resultados de vendas individuais antes de obter informação adicional; 2 . as plausibilidades de obter três niveis diferentes de previsão dados os três resultados reais de vendas. Um exame da seqüência de eventos na figura 3 revela que estas probabilidades não são iguais às requeridas para computar os valores médios ponderados ou "esperados" das diversas estratégias, no gráfico de decisão. Necessita-se basicamente estimar as plausibilidades dos três níveis de resultados da procura real, caso ocorraum dos três níveis de previsão, e as propabilidades totais de cada uma das três estimativas, levando em conta as projeções prévias. 
Tabela 2

Probabilidades posteriores relativas a três níveis de previsão

\begin{tabular}{|c|c|c|c|c|}
\hline $\begin{array}{c}\text { Nível real } \\
\text { das } \\
\text { vendas }\end{array}$ & $\begin{array}{c}\text { Probabilidades } \\
\text { prévias }\end{array}$ & $\begin{array}{l}\text { Probabilidades } \\
\text { condicionadas }\end{array}$ & $\begin{array}{l}\text { Probabilidades } \\
\text { conjuntas }\end{array}$ & $\begin{array}{c}\text { Probabilidades } \\
\text { posteriores }\end{array}$ \\
\hline \multicolumn{5}{|c|}{ Bloco de previsão de vendas altas } \\
\hline Altas & 0,2 & 0,6 & 0,12 & 0,480 \\
\hline Médias & 0,5 & 0,2 & 0,10 & 0,400 \\
\hline Baixas & 0,3 & 0,1 & 0,03 & 0,120 \\
\hline \multicolumn{5}{|c|}{ Probabilidade de previsão de vendas altas 0,25} \\
\hline \multicolumn{5}{|c|}{ Bloco de prevísão de vendas médias } \\
\hline Altas & 0,2 & 0,3 & 0,06 & 0,143 \\
\hline Médias & 0,5 & 0,6 & 0,30 & 0,714 \\
\hline Baixas & 0,3 & 0,2 & 0,06 & 0,143 \\
\hline \multicolumn{5}{|c|}{ Probabilidade de previsão de vendas médias 0,42} \\
\hline \multicolumn{5}{|c|}{ Bloco de previsão de vendas baixas } \\
\hline Altas & 0,2 & 0,1 & 0,02 & 0,061 \\
\hline Médias & 0,5 & 0,2 & 0,10 & 0,303 \\
\hline Baixas & 0,3 & 0,7 & 0,21 & 0,636 \\
\hline \multicolumn{5}{|c|}{ Probabilidade de previsão de vendas baixas 0,33} \\
\hline
\end{tabular}

Todas estas estimativas são necessárias porque as probabilidades devem ser atribuídas aos eventos na ordem em que estes irão ocorrer. Logo, a "previsão" deve anteceder a "procura", e a plausibilidade de certo montante de procura, nos 18 ramos previsionais da figura 3, deve ficar condicinada a uma previsão anterior. Felizmente, o cálculo das probabilidades exigidas com base nas estimadas requer o emprego de operações aritméticas simples, consoante se resume na tabela 2. Doze probabilidades devem ser estimadas. Nove dizem respeito a combinações de previsões e níveis de procura e as outras três relacionam-se com plausibilidades totais de se obter determinada previsão.

Verifica-se na tabela 2 que cada resultado previsional é identificado por um bloco separado. Os procedimentos de cálculo são iguais para cada bloco. Multiplicam-se as probabilidades prévias e condicionadas em cada linha para se conseguir os valores consignados na coluna das probabilidades conjuntas. Estas são somadas na coluna de cada bloco para se estimar as probabilidades totais de cada um dos três resultados previsionais. Se dividirmos cada uma das probabilidades conjuntas pela plausibilidade de previsão do mesmo bloco, acharemos as probabilidades posteriores, como se observa na última coluna da tabela 2. Computam-se as probabilidades posteriores após a coleta da informação adicional - em nosso caso, depois de realizada uma previsão - , com fundamento em todas as informações disponiveis ou presumidas. O leitor poderá verificar como as probabilidades calculadas na tabela 2 foram transferidas para a árvore de decisão da figura 3. O teorema ou regra de Bayes é um instrumento essencial ao cômputo das probabilidades posteriores ou revisadas, isto é, plausibilidades que foram estimadas após a obtenção de informação amostral, experimental ou adicional (ver anexo 1).

Para exemplificar os cálculos, lembramos que a probabilidade conjunta de ocorrência de uma previsão de vendas altas e de uma venda real elevada é dada pela multiplicação de 0,2 por 0,6 , ou 0,12 , enquanto que a probabilidade conjunta de previsão de vendas altas e demanda real baixa é 0,3 vezes 0,1 , ou 0,03 . A plausibilidade total de se obter uma previsão de vendas altas é de 0,25 , ou a soma de $0,12,0,10$ e 0,03 . A probabilidade posterior de ocorrer procura média, dada uma previsão de vendas altas, é fornecida por 0,10 divididos por 0,25 , ou 0,4 . Por outro lado, examinando-se o segundo bloco, verifica-se que a probabilidade posterior de vendas médias, condicionada a uma previsão de vendas baixas, resulta da divisão de 0,10 por 0,33 ou 0,303 .

O método que acabamos de ilustrar é perfeitamente geral para quaisquer conjuntos de eventos e resultados discretos de informação adicional. $O$ número de blocos a computar é idêntico ao número de valores discretos diferentes da informação complementar (neste caso, três resultados previsionais). A quantidade de linhas de computação, dentro de cada bloco, iguala o montante de eventos discretos. As probabilidades prévias e posteriores, consignadas em cada bloco, devem somar 1. A edição das plausibilidades relativas à previsão total, ou das referentes à informação adicional total, deve corresponder também a uma unidade.

Mostram-se os valores dos resultados finais na parte extrema direita da figura 3 . Estas são as mesmas cifras, associadas com diferentes níveis de vendas e decisões de expansão, utilizadas anteriormente. Os montantes decorrentes das decisões ótimas aparecem dentro de balões em nós de decisão (representados por quadrados). A decisão de aumentar as instalações produtivas da firma acompanha uma previsão de vendas altas ou médias, ao passo que a decisão de "não aumentar" corresponde à ocorrência de uma previsão de vendas baixas. $\mathrm{Pa}$ ra conveniência, cortam-se os ramos não-ótimos com linhas curtas. Os números dentro de balōes sobre nós de acaso (representados por circunferências) indicam os valores esperados dos conjuntos seguintes de ramos de eventos.

A determinação dos valores "esperados" das decisões utiliza o mesmo tipo de média, ponderada pelas 
probabilidades de ocorrência dos eventos incertos, que foi empregada nas diversas ocasiões precedentes, porém agora precisamos de dois estágios de computação de médias. As plausibilidades indicadas nos ramos de previsão são as que foram estimadas na figura 3.

Para ilustrar, vejamos como se determina o resultado decorrente de uma previsão de vendas altas e a tomada de decisão favorável ao aumento da capacidade instalada da fábrica.

$$
\begin{aligned}
& 0,48(\mathrm{Cr} \$ 4.000)+0,40(\mathrm{Cr} \$ 1.000)+0,12(-\mathrm{Cr} \$ 1.000) \\
& =\mathrm{Cr} \$ 2.200 .
\end{aligned}
$$

O valor esperado de previsão de vendas altas e a opção de não ampliar a capacidade produtiva da fábrica é:

$$
\begin{aligned}
& 0,48(-\mathrm{Cr} \$ 3.400)+0,40(-\mathrm{Cr} \$ 400)+0,12(\mathrm{Cr} \$ 600) \\
& =\mathrm{Cr} \$ 1.700 .
\end{aligned}
$$

Expectativa de previsão de vendas médias e decisão de aumentar:

$0,143(\mathrm{Cr} \$ 4.000)+0,714(\mathrm{Cr} \$ 1.000)+0,143(-$ Cr $\$ 1.000)=$ Cr\$1.143.

Os valores esperados registrados na porção direita da figura 3, assinalados dentro de balōes, devem ser combinados, novamente, com as probabilidades previsionais funcionando como pesos, a fim de se obter um valor único "esperado", referente à alternativa de usar o serviço de previsão de vendas. O cálculo é o seguinte: $0,25(\mathrm{Cr} \$ 2.200)+0,42(\mathrm{Cr} \$ 1.143)+0,33(\mathrm{Cr} \$ 53)=$
$\mathrm{Cr} \$ 1.047 .55$

Comparando-se com a análise prévia, o valor esperado da informação adicional gerada pelo serviço de previsão de vendas é Cr $\$ 47,55$ (de Cr $\$ 1.047,55-$ Cr\$1.000).

Examinemos alguns resultados contidos na figura 3. Em situação de análise prévia, isto é, sem acesso à informação adicional, o tomador de decisão escolhe a alternativa de "aumentar a capacidade produtiva da fábrica" e obtém um ganho médio esperado de Cr $\$ 1.000$, contra uma perda de oportunidade esperada de Cr $\$ 700$, caso sua opção preferencial seja pela estratégia de "não ampliar as instalações da fábrica". "Com a aquisição do serviço de previsão de vendas, seus ganhos esperados serão de Cr $\$ 2.200$ e Cr $\$ 1.143$ nas hipóteses de ocorrência de previsão de vendas altas e médias, respectivamente, ambas superiores ao ganho incremental de apenas $\mathrm{Cr} \$ 1.000$, conseqüente à decisão de não contratar o serviço de previsão. Caso esse serviço indicasse vendas baixas, a opção por aumentar a capacidade de produção levaria a um resultado inferior à mesma decisão baseada na análise prévia e sem recurso ao método previsional (prejuízo incremental de Cr\$89, contra um ganho adicional de $\mathrm{Cr} \$ 1.000$ ). O ganho médio esperado de contratar o serviço de previsão seria de Cr $\$ 1.047,55$, contra $\mathrm{Cr} \$ 1.000$, resultantes da opção de não contratar.
O montante de Cr $\$ 47,55$ (Cr $\$ 1.047,55$ - Cr $\$ 1.000$ ) chama-se Valor Esperado da Informação Imperfeita e é simbolizado pela sigla VEH. Se o tomador de decisão avaliar uma escolha entre empreender uma ação terminal imediata, sem obter informação adicional, e contratar o serviço de previsão de vendas e, posteriormente, optar por uma ação terminal, o Valor Esperado da Informação Imperfeita representa o ganho esperado que seria acrescido ao lucro marginal da estratégia terminal pela existência de informação amostral. Esta importância seria, também, o montante máximo que o tomador de decisão estaria inclinado a pagar pelo serviço de previsão de vendas.7

Como a informação previsional custaria apenas Cr $\$ 10,00$ (Cr $\$ 10$ milhões), o administrador decidiu recorrer ao serviço de previsão de vendas. $O$ valor marginal esperado desta decisão foi Cr\$37,55, ou Cr $\$ 47,55$ menos o custo de $\mathrm{Cr} \$ 10,00$. O valor esperado do serviço de previsão foi ajustado também na figura 3, a fim de refletir o custo de $\mathrm{Cr} \$ 10,00$ da previsão. Como o histórico do serviço de previsão de vendas está longe de ser perfeito, conforme se depreende das probabilidades não-nulas das previsões divergentes das vendas reais na figura 3, o valor esperado da informação adicional de Cr $\$ 47,55$ é bastante inferior à quantia de Cr $\$ 480$, que é o valor esperado da informação perfeita computado no item anterior. Observe-se que se a probabilidade de uma previsão correta fosse $100 \%$, tornando nula a plausibilidade de um "furo" da estimativa, o valor esperado da informação imperfeita coincidira com o VEIP de Cr\$480.

Denomina-se pré-posterior a análise que acabamos de realizar, visto que ela é completada antes de se colher informação incremental. A decisão envolvida neste programa diz respeito à opção de contratar ou não um serviço de previsão de vendas, e é apenas antecipadora com relação à conseqüência da informação de determinado resultado de previsão de vendas. Por esta razão, a análise apóia-se ainda nas probabilidades originais de vendas formuladas pelo tomador de decisão da análise prévia.

O administrador não deve, todavia, prender-se permanentemente a essas estimativas subjetivas originais. Demonstramos que o lucro esperado aumentará se o serviço de previsão for contratado e utilizado. No momento em que esse serviço gerar informação adicional, as probabilidades prévias atribuídas pelo administrador aos diversos niveis de procura deveriam ser revisadas. Dever-se-iam calcular novos valores esperados com base nas plausibilidades revisadas, que aparecem na coluna de probabilidades da tabela 2. Como já foi assinalado, o valor esperado da decisão de "aumentar", após o recebimento de uma previsão de vendas altas, é de Cr\$2.200. Convém ressaltar mais uma vez que a análise de decisão é um processo de melhoria progressiva. Seria possível reutilizar o sistema cada vez que alguma informação nova fosse colhida.

Este item ilustrou também a ampliação dos modelos de análise de decisão. Vimos os resultados da figua 2 , baseada em análise prévia, incorporados à figura 3 , fundamentada na análise pré-posterior, e no cálculo, em dois estágios, do valor esperado do serviço de previsão. 
É claro que os resultados apresentados na figura 3 poderiam ter sido incluídos num sistema de decisão mais amplo, e que a análise de estágios múltiplos obedeceria o mesmo esquema que a decisão em dois estágios. É importante que cada evento sucessivo de uma estratégia de decisão seja seqüenciado como decorrência dos que antecederam.

Para finalizar, calculemos o Valor Esperado Posterior da Informação Perfeita, simbolizado por VEIP 1 (para distinguir do Valor Esperado Prévio da Informação Perfeita, representado por VEIPo):'

Previsão de vendas altas

$\mathrm{VEIP}_{1}=\mathrm{LE}_{1} / \mathrm{IP}-\mathrm{DO}_{1} / \mathrm{SI}=$ Lucro Esperado Posterior, dada a Informação Perfeita - Decisão Ótima Posterior em Situação de Incerteza.

$=0,48(\mathrm{Cr} \$ 4.000)+0,40(\mathrm{Cr} \$ 1.000)+0,12$ $(\mathrm{Cr} \$ 600)-\mathrm{Cr} \$ 2.200=\mathrm{Cr} \$ 2.392-\mathrm{Cr} \$ 2.200=$ Cr $\$ 192$.

Comparando-se com o valor esperado da informação perfeita computado anteriormente (Cr\$480), conclui-se que a contratação do serviço de previsão de vendas contribuiu substancialmente para reduzir o preço máximo que o tomador de decisão estaria disposto a pagar por informação perfeita, pois esta quantia não ultrapassaria, agora, Cr\$192.

Previsão de vendas médias

VEIP $_{1}=0,143(\mathrm{Cr} \$ 4.000)+0,714(\mathrm{Cr} \$ 1.000)+$ $0,143(\mathrm{Cr} \$ 600)-\mathrm{Cr} \$ 1.143=\mathrm{Cr} \$ 1.371,8-\mathrm{Cr} \$ 1.143=$ Cr\$228,8.

Previsão de vendas baixas

$\mathrm{VEIP}_{1}=0,061(\mathrm{Cr} \$ 4.000)+0,303(\mathrm{Cr} \$ 1.000)+$ $0,0636(\mathrm{Cr} \$ 600)-\mathrm{Cr} \$ 53=\mathrm{Cr} \$ 585,16-\mathrm{Cr} \$ 53=$ Cr\$532, 16 .

$\mathrm{Na}$ hipótese de previsão de vendas médias, verifica-se que o valor esperado da informação perfeita reduziu-se menos: de $\mathrm{Cr} \$ 480$ para $\mathrm{Cr} \$ 228,8$. Se o serviço de previsão concluir, todavia, que as vendas do novo produto serão baixas, o valor esperado da informação perfeita aumentará de Cr\$480 para Cr\$532,16.

\section{ANALISE DE SENSIBILIDADE}

A análise de sensibilidade examina as conseqüências de variação incremental. Até que limite o tomador de decisão poderia modificar sua avaliação subjetiva de probabilidades antes que a decisão ótima fosse alterada? $\mathrm{Na}$ decisão prévia, demonstrou-se que uma variação da aferição subjetiva de probabilidades, pelo administrador, dosíndices originais até plausibilidades iguais, para o elenco dos níveis de vendas do novo produto, não foi suficiente para mudar a decisão ótima de expandir. Em quanto as probabilidades poderiam ser alteradas antes que a decisão de "não expandir" substituísse a de "expandir" como o valor ótimo? Formalmente, esta questão corresponde à estipulação de índices aleatórios na condição-limite, em que os valores esperados das duas estratégias seriam iguais, porque significa determinar o ponto de indiferença entre estratégias.

No problema analisado neste artigo, seria necessária uma probabilidade relativamente alta de vendas baixas antes que a decisão de não expandir passasse a ser ótima. Suponhamos que a probabilidade de vendas médias fosse mantida no nivel neutro de 0,3 e que as plausibilidades de vendas altas $\mathrm{e}$ baixas fossem computadas de modo a igualizar os valores esperados das duas estratégias "expandir" e "não expandir". Se $p$ simbolizar a probabilidade de vendas baixas, $(1-0,3-p)$ ou $(0,7$ - p) representará a possibilidade de vendas altas. Isto decorre do fato de que as probabilidades de todos os níveis de vendas devem somar 1 ( ou $100 \%$ ). Com base nos valores das estratégias da figura 2 no item sobre análise prévia, podemos estabelecer a seguinte igualdade:

Valor Esperado da Ação $A_{1}$ ("expandir") = Valor Esperado da Ação $A_{2}$ ("não expandir"), ou $(0,7-p)(C r \$ 4.000)+0,3(C r \$ 1.000)+p(-C r \$ 1.000)$ $=(0,7-\mathrm{p})(-\mathrm{Cr} \$ 3.400)+0,3(-\mathrm{Cr} \$ 400)+\mathrm{p}(\mathrm{Cr} \$ 600)$

Solucionando a equação anterior, teremos:

$\mathbf{p}=\mathbf{0}, \mathbf{6 2}$, probabilidade de vendas baixas, $(1-0,3-p)=0,08$, probabilidade de vendas altas e 0,3 $=$ probabilidade estabelecida de vendas médias.

Nesses níveis de plausibilidade, o tomador de decisão ficaria indiferente entre optar por "expandir" e "não expandir", porque os valores esperados de ambas as estratégias seriam iguais. Mesmo assim, o administrador poderia selecionar uma estratégia em lugar de outra com base em informação auxiliar não abrangida por esta análise quantitativa.

Voltando aos cálculos, se a probabilidade de vendas baixas exceder $62 \%$, e, por conseguinte, a plausibilidade de vendas altas cair abaixo de $8 \%$, o tomador de decisão preferiria a ação "não expandir", já que o valor esperado da estratégia "expandir" seria inferior ao da estratégia "não expandir". Para uma probabilidade de vendas baixas menor do que $62 \% \mathrm{e}$, portanto, de vendas altas maior do que $8 \%$, o tomador de decisão preferiria a estratégia "expandir", porque seu valor monetário esperado seria superior ao da estratégia "não expandir".

As considerações anteriores ilustram uma análise de sensibilidade para valores limites de probabilidades num ponto de mudança entre estratégias ótimas. Sistemas adequados de equações podem ser formulados para determinar os conjuntos de plausibilidades referentes aos diversos limites de indiferença entre estratégias. Se as avaliações de probabilidades do administrador estiverem perfeitamente contidas em limites, como é o caso do problema analisado neste artigo, ele não deverá preocupar-se desnecessariamente com a precisão de suas estimativas.

É claro que o número de cálculos dos valores esperados dos ramos de decisão e a variedade de computações relativas aos limites de probabilidades, para efeitos de análise de sensibilidade, aumentarão rapidamente à medida que crescer a complexidade da situação de decisão. Este fato não deve eliminar, contudo, a busca de 
informações adicionais, visto que programas de computação foram desenvolvidos para preparar os cálculos. O administrador deverá compreender o sistema de análise de decisão, de modo a poder supervisionar a coleta de informações e a lógica dos passos envolvidos na decisão.

\section{TEORIA BAYESIANA DE DECISÃO}

A teoria bayesiana de decisão combina probabilidades subjetivas e objetivas com plausibilidades revisadas. Estas últimas resultam do emprego de informações atualizadas, tais como as que se obtêm mediante pesquisas, amostragem, experimentação, testes e estudos de mercado, com a colaboração de fornecedores, vendedores, distribuidores, consultores e outras pessoas ou organizações, que possam exercer alguma influência sobre a previsão de vendas. Esta estimativa final decorre, essencialmente, de uma revisão da projeção inicial a partir da disponibilidade de informação relevante.

O problema que apresentaremos nesta parte de nosso artigo constitui a adaptação de uma situação semelhante, descrita por Gross e Paterson. ${ }^{8}$

O gerente de vendas de determinada firma solicitou ajuda de seu assistente de análise e estatística de vendas para a preparação de uma previsão de vendas de um produto novo, que a empresa está planejando lançar. Os resultados da estimativa de vendas servirão de base para se decidir se o novo produto será ou não introduzido no mercado.

Após algumas reuniões com o gerente de vendas, e tendo formado uma opinião sobre o mercado, o assistente de análise e estatística de vendas decidiu que o mercado poderá ser bom, regular ou ruim para o novo produto, dependendo de fatores como disponibilidade de matéria-prima e preços, condições econômicas, atua- ção dos concorrentes, comportamento dos intermediários e dos consumidores, condições climáticas e demais variáveis não-controláveis pela administração da empresa. O gerente de vendas e outras pessoas conhecedoras do mercado, incluindo alguns executivos da companhia, não crêem que cada evento possível tenha uma probabilidade igual de ocorrência. Ao contrário, chegou-se a um consenso de que as probabilidades subjetivas apresentadas a seguir representam as plausibilidades de sucesso de cada um destes eventos incertos:

\begin{tabular}{cc}
\hline $\begin{array}{c}\text { Eventos } \\
\left(E_{i}\right)\end{array}$ & $\begin{array}{c}\text { Probabilidades prévias } \\
\text { dos eventos } E_{1}-P\left(E_{1}\right)\end{array}$ \\
\hline
\end{tabular}

$E_{1}=O$ mercado é bom para o novo

produto $\quad 0,2$

$\mathrm{E}_{2}=\mathrm{O}$ mercado é regular para o novo

produto

0,7

$\mathrm{E}_{3}=\mathrm{O}$ mercado é ruim para o novo

produto

Total

0,1

1,0

Duas ações são analisadas neste momento:

$A_{1}$ : lançar o novo produto sem qualquer consulta ao mercado.

$\mathbf{A}_{2}$ : não lançar o novo produto.

Os ganhos incrementais decorrentes da decisão de lançar o novo produto dependerão, obviamente, das condições do mercado, isto é, os eventos incertos $E_{i}$. As perdas de oportunidade conseqüentes à decisão de não lançar o novo produto estarão associadas às situações vigentes no mercado. $O$ gerente de vendas, em seguida a uma reunião com o gerente financeiro, estimou os ganhos (prejuízos) marginais resultantes de lançamento (ou abandono) do novo produto, sob as diversas condições previstas de mercado, apresentados nas tabelas 3 e 4.

Tabela 3

Matriz de ganhos ou perdas do lançamento do novo produto

\begin{tabular}{lccr}
\hline $\begin{array}{l}\text { Eventos } \\
\left(\mathrm{E}_{\mathrm{i}}\right)\end{array}$ & $\begin{array}{c}\text { Lucro/prejuizo } \\
\text { marginal } \\
\text { prévias }-\mathrm{P}\left(\mathrm{E}_{\mathrm{i}}\right)\end{array}$ & $\begin{array}{c}\text { Lucro/prejuizo } \\
\text { marginal } \\
\text { (Em Cr\$ 1 milhão) }\end{array}$ & $\begin{array}{c}\text { ponderado } \\
\mathrm{E}_{1}: \text { Mercado bom }\end{array}$ \\
$\mathrm{E}_{2}:$ Mercado regular & 0,2 & 80.000 & 16.000 \\
$\mathrm{E}_{3}:$ Mercado ruim & 0,7 & -4000 & 1.400 \\
& 0,1 & & -4.000 \\
\hline
\end{tabular}

Tabela 4

Matriz de ganhos ou perdas do abandono do novo produto

\begin{tabular}{lccr}
\hline $\begin{array}{l}\text { Eventos } \\
\left(\mathrm{E}_{\mathbf{i}}\right)\end{array}$ & $\begin{array}{c}\text { Probabilidades } \\
\text { prévias }-\left(\mathrm{E}_{\mathbf{i}}\right.\end{array}$ & $\begin{array}{c}\text { Lucro/prejuizo } \\
\text { marginal } \\
\text { (Em Cr\$ 1 milhão) }\end{array}$ & $\begin{array}{c}\text { Lucro/prejuízo } \\
\text { marginal } \\
\text { ponderado }\end{array}$ \\
\hline $\mathrm{E}_{1}:$ Mercado bom & 0,2 & -64.000 & -12.800 \\
$\mathrm{E}_{2}:$ Mercado regular & 0,7 & -800 & -560 \\
$\mathrm{E}_{3}:$ Mercado ruim & 0,1 & 30.000 & 3.000 \\
& & & $-\mathrm{Cr} \$ 10.360$ \\
\hline
\end{tabular}


O Valor Monetário Esperado (VME) da ação $A_{1}$ é:

$\operatorname{VME}\left(\mathrm{A}_{1}=0,2(\mathrm{Cr} \$ 80.000)+0,7(\mathrm{Cr} \$ 2.000)+0,1\right.$ $(-\mathrm{Cr} \$ 40.000)$

$=\mathrm{Cr} \$ 16.000+\mathrm{Cr} \$ 1.400-\mathrm{Cr} \$ 4.000=\mathrm{Cr} \$ 13.400$

O Valor Monetário Esperado da ação $A_{2}$ é:

$\operatorname{VME}\left(\mathrm{A}_{2}=0,2(-\mathrm{Cr} \$ 64.000)+0,7\right.$

$(-\mathrm{Cr} \$ 800)+0,1(\mathrm{Cr} \$ 30.000)=$

$-\mathrm{Cr} \$ 12.800-\mathrm{Cr} \$ 560+\mathrm{Cr} \$ 3.000=-\mathrm{Cr} \$ 10.360$

O lucro marginal esperado da ação $A_{1}$ mostra que a firma deveria lançar o novo produto, com base nas probabilidades subjetivas e nas estimativas do lucro realizável sob as várias condições de mercado. O lucro marginal esperado de $\mathrm{Cr} \$ 13.400$, decorrente do lançamento do novo produto, é superior à perda de oportunidade esperada de $\mathrm{Cr} \$ 10.360$ associada ao abandono do projeto.

O cálculo do Valor Esperado da Informação Perfeita (VEIP) relativa ao projeto do novo produto é o seguinte:

Lucro Esperado Condicionado à Existência de Informação Perfeita-Decisão Ótima em Situação de Incerteza $=\mathrm{LE} / \mathrm{IP}-\mathrm{DO} / \mathrm{SI}=\mathrm{VEIP}=\mathbf{0 , 2}(\mathrm{Cr} \$ 80.000)$ $+0,7(\mathrm{Cr} \$ 2.000)+0,1(\mathrm{Cr} \$ 30.000)-\mathrm{Cr} \$ 13.400=$ $(\mathrm{Cr} \$ 16.000+\mathrm{Cr} \$ 1.400+\mathrm{Cr} \$ 3.000)-\mathrm{Cr} \$ 13.400=$ VEIP $=$ Cr $\$ 20.400-\operatorname{Cr} \$ 13.400=\mathrm{Cr} \$ 7.000$

A importância de Cr $\$ 7$ bilhões seria o valor máximo que o gerente de vendas da empresa estaria disposto a pagar por uma informação perfeita sobre a ocorrência dos três eventos incertos, ou seja, o desembolso de fundos que lhe seria permitido fazer para reduzir a zero o atual estado de incerteza no processo decisório de lançar ou não o novo produto no mercado.

A análise prévia das duas estratégias disponíveis, lançar o novo produto agora, sem qualquer consulta ao mercado, ou abandonar o projeto, revela que o lucro marginal esperado da primeira é superior em $\mathrm{Cr} \$ 13.400$ $-(-\mathrm{Cr} \$ 10.360)=\mathrm{Cr} \$ 23.760$ ao da segunda. Como existe uma situação de incerteza vinculada à tomada de decisão neste momento, seria altamente desejável, para o gerente de vendas, averiguar em quanto poderiam ser alteradas as possibilidades de ocorrência dos três eventos antes que fosse necessário modificar a decisão de lançar o novo produto pela de abandonar o projeto.

Suponhamos que a probabilidade de sobrevir um mercado regular para o novo produto seja confirmada em torno de $50 \%$ e que as plausibilidades de mercado bom e ruim sejam estimadas de modo a igualar as duas estratégias "lançar o novo produto" e "abandonar o projeto". Se $p$ representar a probabilidade de um mercado ruim $(1-0,5-p)$ ou $(0,5-p)$ corresponderá à plausibilidade de acontecer um mercado bom. Calcularemos, a seguir, o valor de $p$.

Valor esperado da ação $A_{1}$ ("lançar o novo produto")
= Valor esperado da ação $\mathbf{A}_{2}$ ("'abandonar o projeto"') ou

$(0,5-\mathrm{p})(\mathrm{Cr} \$ 80.000)+0,5(\mathrm{Cr} \$ 2.000)+\mathrm{p}(-$ $\mathrm{Cr} \$ 40.000)=$

$(0,5-p)(-C r \$ 64.000)+0,5(-\operatorname{Cr} \$ 800)+p$ (Cr\$30.000).

Resolvendo a equção, tem-se:

$p=0,343$, probabilidade de ocorrer um mercado ruim.

$(1-0,5-p)=0,157$, probabilidade de suceder um mercado bom,

$0,5=$ plausibilidade assumida de acontecer um mercado regular.

Estes cálculos demonstram que, para igualar os ganhos esperados das duas estratégias, seria necessário que a probabilidade de mercado ruim subisse de 0,1 para 0,343 e que a plausibilidade de mercado bom baixasse de 0,2 para 0,157 . Por fim, a probabilidade de mercado regular precisaria descer de 0,7 para 0,5 .

Se a probabilidade de mercado ruim ultrapassar $34,3 \%$ e, por conseguinte, a plausibilidade de mercado bom cair abaixo de $15,7 \%$, o gerente de vendas optará pela estratégia de "abandonar o projeto", porque seu ganho esperado será maior do que o lucro esperado da estratégia de "lançar o novo produto". No caso de suceder mercado ruim com probabilidade inferior a $34,3 \%$ e, portanto, a plausibilidade de mercado bom ser superior a $15,7 \%$, a opção preferencial será pela estratégia de "lançar o novo produto".

Infelizmente, a maioria das decisões e estimativas de vendas não é formulada tão simplesmente quanto o exemplo anterior permite deduzir. Muitas delas são bem mais complexas, freqüentemente complicadas pela existência de diversas alternativas. A análise bayesiana faculta a investigação de problemas mais amplos e complexos mediante o uso dos conceitos de valor esperado como base de comparação.

Para ilustrar, suponhamos que o gerente de vendas deseje obter maiores informações sobre o mercado do novo produto que sua empresa pretende lançar. Uma possibilidade envolveria a realização de um projeto de pesquisa, que tentaria avaliar o mercado e possibilitar a elaboração de uma estimativa de vendas do novo produto com base nas informações coletadas. Após a conclusão da pesquisa, tomar-se-ia a decisão de lançar o novo produto ou abandonar o projeto. A previsão de vendas poderá ajudar o gerente de vendas através da mensuração do potencial de mercado após o recebimento das informações de pesquisa, e pela sua capacidade de determinar se a informação adicional vale ou não o seu custo de obtenção.9

Após uma avaliação das alternativas possíveis, $o$ assistente de análise e estatística de vendas informou ao gerente de vendas que dois projetos de pesquisa poderiam ser considerados. São os seguintes:

\subsection{Plano de Pesquisa}

Realizar um estudo de mercado rápido, com duração de dois meses, de $30 \%$ dos revendedores potenciais e 
uma investigação de todos os clientes de 10 pontos de venda do produto durante o período de um mês. Os clientes deverão responder um pequeno questionário dirigido à obtenção de informações sobre as características que eles desejam num prcduto semelhante ao que se pretende lançar, bem como suas intenções de compra.

Estimou-se que o custo dessa pesquisa seria de $\mathrm{Cr} \$$ 45 milhões. Como a investigação de mercado causará um adiamento do lançamento do novo produto, decidiu-se que o lucro marginal estimado deveria ser reduzido de $5 \%$ em relação ao que seria se a introdução fosse imediata, isto é, esperar-se que os esforços dos concorrentes e outras forças de mercado diminuam o mercado potencial em $5 \%$, se o lançamento for retardado por dois meses.

Por outo lado, a previsão aumentará com a existência de dados colhidos no mercado. Se o lançamento ocorrer imediatamente, não existirá informação objetiva disponível que indique se existe ou não um mercado bom, ruim ou regular para o novo produto. Com informação amostral, contudo, a estimativa de vendas poderá ser formulada com base em dados mais "reais". Após a coleta de informações, será possível elaborar uma estimativa de mercado bom, regular ou ruim, que poderá influenciar a decisão de lançar o novo produto. Com base em dados experimentais colhidos no passado, o gerente de vendas estimou que a previsão resultante teria uma probabilidade de $80 \%$ de ser correta. A plausibilidade de $20 \%$ da projeção ser incorreta seria dividida igualmente ( $10 \%$ para cada) entre as outras duas categorias de condição de mercado. Em símbolos, são estas as probabilidades prévias e condicionadas:

\section{- Probabilidades prévias}

$P(B)=P$ ("mercado bom") $=0,2$

$P(R)=P$ ("'mercado regular") $=0,7$

$P(F)=P($ ("mercado ruim") $=0,1$.

\section{- Probabilidades condicionadas}

$\mathrm{Z}_{1}=$ evento relacionado com a previsão de "mercado bom",

$\mathrm{Z}_{2}$ = evento relacionado com a previsão de "mercado regular",

$\mathrm{Z}_{3}=$ evento relacionado com a previsão de "mercado ruim".

$\mathrm{P}\left(\mathrm{Z}_{1} / \mathrm{B}\right)=0,8-$ probabilidade de previsão de "mercado bom", dado que o mercado é bom,

$P\left(Z_{1} / R\right)=0,1$ - probabilidade de previsão de "mercado bom", dado que o mercado é regular,

$P\left(Z_{1} / F\right)=0,1$ - probabilidade de previsão de "mercado bom", dado que o mercado é ruim.

As probabilidades condicionadas relativas aos demais eventos seriam simbolizadas de maneira idêntica.

\subsection{Plano de Pesquisa B}

O gerente de veudas poderia optar por um projeto de pesquisa mais demorado e, por conseguinte, mais con- fiável. $O$ estudo de mercado abrangeria um perído de três meses, porém incluiria $40 \%$ dos revendedores potenciais e uma investigação junto a todos os clientes de 20 pontos de venda, escolhidos ao acaso, no intervalo de um mês.

Este estudo seria similar ao do plano A, com a diferença de que seria mais longo e mais caro. Estimou-se o custo desse projeto em torno de $\mathrm{Cr} \$ 150$ milhões e que o valor do mercado sofreria uma perda de $10 \%$ se o lançamento do novo produto não ocorresse imediatamente.

O nível de confiabilidade deste projeto de pesquisa deverá ser substancialmente maior do que o do plano A. Neste caso, calcula-se que a previsão resultante teria uma probabilidade de $90 \%$ de ser correta. O fator de erro de $10 \%$ seria dividido igualmente entre as duas classes restantes de condição de mercado.

\subsection{Análises dos planos de pesquisas A e B}

Os planos de pesquisa A e B devem ser avaliados à luz dos decrementos previstos nos lucros ou prejuízos realizáveis sob cada uma das três condições possíveis de mercado. Com a antecipação de que o mercado será $5 \%$ menor se a decisão de fazer pesquisa for tomada, os potenciais de mercado projetados serão os seguintes, de acordo com o plano A:

\begin{tabular}{lcc} 
Eventos $\left(\mathrm{E}_{\mathbf{i}}\right.$ & $\begin{array}{c}\text { Probabilidades } \\
\text { prévias }-\mathrm{P}\left(\mathrm{E}_{\mathbf{i}}\right)\end{array}$ & $\begin{array}{c}\text { Lucro/prejuizo realizável } \\
(\mathrm{Cr} \text { 1 milhão) }\end{array}$ \\
\hline $\mathrm{E}_{1}:$ Mercado bom & 0,2 & $\cdot 76.000$ \\
$\mathrm{E}_{2}:$ Mercado regular & 0,7 & 1.900 \\
$\mathrm{E}_{3}:$ Mercado ruim & 0,1 & $-\mathbf{4 2 . 0 0 0}$ \\
\hline
\end{tabular}

A pesquisa de mercado a ser realizada, segundo as condições descritas no plano A, tem uma confiabilidade de $80 \%$ de proporcionar estimativas de vendas corretas do novo produto a ser lançado no mercado.

Da mesma forma que o plano A, a avaliação do plano $B$ começa com a determinação dos resultados de lucro ou prejuizo atingíveis sob cada um dos possíveis eventos condicionais. Em qualquer um dos três eventos incertos, vaticina-se que o mercado será $10 \%$ menor do que se a introdução do produto for realizada imediatamente, devido à demora de três meses. Deve-se salientar, todavia, que este projeto de pesquisa, em virtude de sua amostra maior, deverá levar a um resultado de projeção da condição de mercado com uma probabilidade de $90 \%$ de estar correta. Os potenciais de mercado antecipados serão estes:

\begin{tabular}{lcc} 
Eventos $\left(\mathrm{E}_{\mathrm{i}}\right)$ & $\begin{array}{c}\text { Probabilidades } \\
\text { prévias }-\mathrm{P}\left(\mathrm{E}_{\mathbf{i}}\right)\end{array}$ & $\begin{array}{c}\text { Lucro/prejuízo realizável } \\
\text { (Cr } \$ 1 \text { milhão) }\end{array}$ \\
\hline $\mathrm{E}_{1}:$ Mercado bom & 0,2 & 72.000 \\
$\mathrm{E}_{2}:$ Mercado regular & 0,7 & 1.800 \\
$\mathrm{E}_{3}:$ Mercado ruim & 0,1 & -44.000 \\
\hline
\end{tabular}

Como vimos na resolução do problema anterior relacionado com a previsão de vendas de um novo pro- 
duto, desenvolveremos a seguir uma análise pré-posterior deste segundo problema de decisão, com vistas a poder responder se o gerente de vendas deveria ou não colher informações amostrais no mercado. Se for provado que a realização da pesquisa será rendosa para a empresa, o método poderá defnir qual dos dois projetos é o melhor, os cursos da ação mais apropriados para cada tipo de resultado amostral, e que o tamanho da amostra a ser colhida.

A análise pré-posterior, como o próprio nome indica, é um tipo de estudo que deve ser excutado antes de coletar informação amostrale, por conseguinte, antes da disponibilidade de probabilidades posteriores fundadas num resultado amostral particular. Este tipo de análise leva em conta, entretanto, todos os possíveis resultados amostrais e computa o ganho esperado (ou a perda de oportunidade esperada) de uma estratégia baseada na escolha das melhores alternativas, dependendo do tipo de informação amostral (ou dado experimental) observando. 10

A tabela 5 registra as probabilidades condicionadas, associadas aos três possíveis resultados da pesquisa de mercado.

Tabela 5

Probabilidades condicionadas dos três tipos de evidência amostral dos planos de pesquisa A e B

\begin{tabular}{|c|c|c|c|c|c|c|c|c|}
\hline \multirow[t]{2}{*}{ Eventos $\left(E_{\mathbf{i}}\right)$} & \multicolumn{5}{|c|}{$\begin{array}{c}\text { Plano de pesquisa } A \\
\text { Probabilidades } \\
\text { condicionadas }-\mathrm{P}\left(\mathrm{Z}_{\mathbf{j}} / \mathrm{E}_{\mathbf{j}}\right)\end{array}$} & \multicolumn{3}{|c|}{$\begin{array}{c}\text { Plano de pesquisa } B \\
\text { Probabilidades } \\
\text { condicionadas }-\mathrm{P}\left(\mathrm{Z}_{\mathrm{j}} / \mathrm{E}_{\mathrm{i}}\right)\end{array}$} \\
\hline & $\mathrm{Z}_{1}$ & $\mathrm{Z}_{2}$ & $\mathrm{Z}_{3}$ & Total & $\mathrm{z}_{1}$ & $\mathrm{Z}_{2}$ & $\mathrm{Z}_{3}$ & Total \\
\hline $\mathrm{E}_{1}:$ Mercado bom & 0,8 & 0,1 & 0,1 & 1,0 & 0,90 & 0,05 & 0,05 & 1,0 \\
\hline $\mathrm{E}_{2}$ : Mercado regular & 0,1 & 0,8 & 0,1 & 1,0 & 0,05 & 0,90 & 0,05 & 1,0 \\
\hline$E_{3}:$ Mercado ruim & 0,1 & 0,1 & 0,8 & 1,0 & 0,05 & 0,05 & 0,90 & 1,0 \\
\hline
\end{tabular}

As tabelas seguintes resumem os cálculos das probabilidades posteriores dos três resultados amostrais possíveis relacionados com o problema de decisão de lançar ou não o novo produto.

O gerente de vendas decidiu levar adiante a análise do problema de decisão de lançar ou não o novo produto e providenciou a preparação do diagrama apresentado na figura 4 . Todos os valores monetários, como de costume, são em milhões de cruzeiros. Voltando ao início do problema, a primeira escolha diz respeito a contratar ou não a pesquisa de mercado (Plano A), que foi oferecida à empresa, pelo valor orçado de $\mathrm{Cr} \$ 45 \mathrm{mi}$ Ihões. Tomando por ponto de partida o nó inferior, indicado na parte esquerda da figura 4 , e prosseguindo ao longo do ramo "Não fazer pesquisa"' do diagrama, atingimos a árvore de decisão básica do problema de optar com fundamento apenas numa análise prévia do pro-

Tabela 6

Probabilidades posteriores dos três resultados amostrais possiveis - plano de pesquisa A

\begin{tabular}{l} 
Eventos $\left(E_{i}\right)$ \\
\hline Resultado da pesquisa \\
mercado bom \\
$E_{1}:$ Mercado bom \\
$E_{2}:$ Mercado regular \\
$E_{3}:$ Mercado ruim
\end{tabular}

Resultado da pesquisa: mercado regular $\mathrm{E}_{1}$ : Mercado bom $\mathrm{E}_{2}$ : Mercado regular $\mathrm{E}_{3}$ : Mercado ruim

Resultado da pesquisa: mercado ruim $\mathrm{E}_{1}$ : Mercado bom $\mathrm{E}_{2}$ : Mercado regular $\mathrm{E}_{3}$ : Mercado ruim
Probabilidades Probabilidades Probabilidades Probabilidades

$\begin{array}{cccc}\text { prévias } & \text { condicionadas } & \text { conjuntas } & \text { posteriores } \\ P\left(E_{j}\right) & P\left(Z_{j} / E_{j}\right) & P\left(Z_{j} / E_{i}\right) & P\left(E_{i} / Z_{j}\right)\end{array}$


Tabela 7

Probabilidades posteriores dos três resultados amostrais possíveis - plano de pesquisa $B$

\begin{tabular}{l} 
Eventos $\left(\mathrm{E}_{\mathbf{i}}\right)$ \\
\hline Resultado da pesquisa: \\
mercado bom \\
$\mathrm{E}_{1}:$ Mercado bom \\
$\mathrm{E}_{2}:$ Mercado regular \\
$\mathrm{E}_{3}:$ Mercado ruim
\end{tabular}

Resultado da pesquisa:

mercado regular

$\mathrm{E}_{1}$ : Mercado bom

$E_{2}$ : Mercado regular

$\mathrm{E}_{3}$ : Mercado ruim
Probabilidades Probabilidades Probabilidades Probabilidades

$\begin{array}{cccc}\text { prévias } & \text { condicionadas } & \text { conjuntas } & \text { posteriores } \\ \mathbf{P}\left(\mathrm{E}_{\mathrm{i}}\right) & \mathbf{P}\left(\mathrm{Z}_{\mathrm{j}} / \mathrm{E}_{\mathrm{i}}\right) & \mathbf{P}\left(\mathrm{Z}_{\mathrm{j}} / \mathrm{E}_{\mathrm{j}}\right) & \mathbf{P}\left(\mathrm{E}_{\mathrm{i}} / \mathrm{Z}_{\mathrm{j}}\right)\end{array}$

\author{
Es: Mercado ruim
}

:

$\begin{array}{cccc}0,2 & 0,90 & 0,180 & 0,819 \\ 0,7 & 0,05 & 0,035 & 0,159 \\ 0,1 & 0,05 & 0,005 & 0,022 \\ \text { Probabilidade } & & 0,220 & 1,000 \\ \text { de } Z_{1} & & & \end{array}$


Figura 4

Análise de decisão com disponibilidade de

informação de pesquisa - Plano A

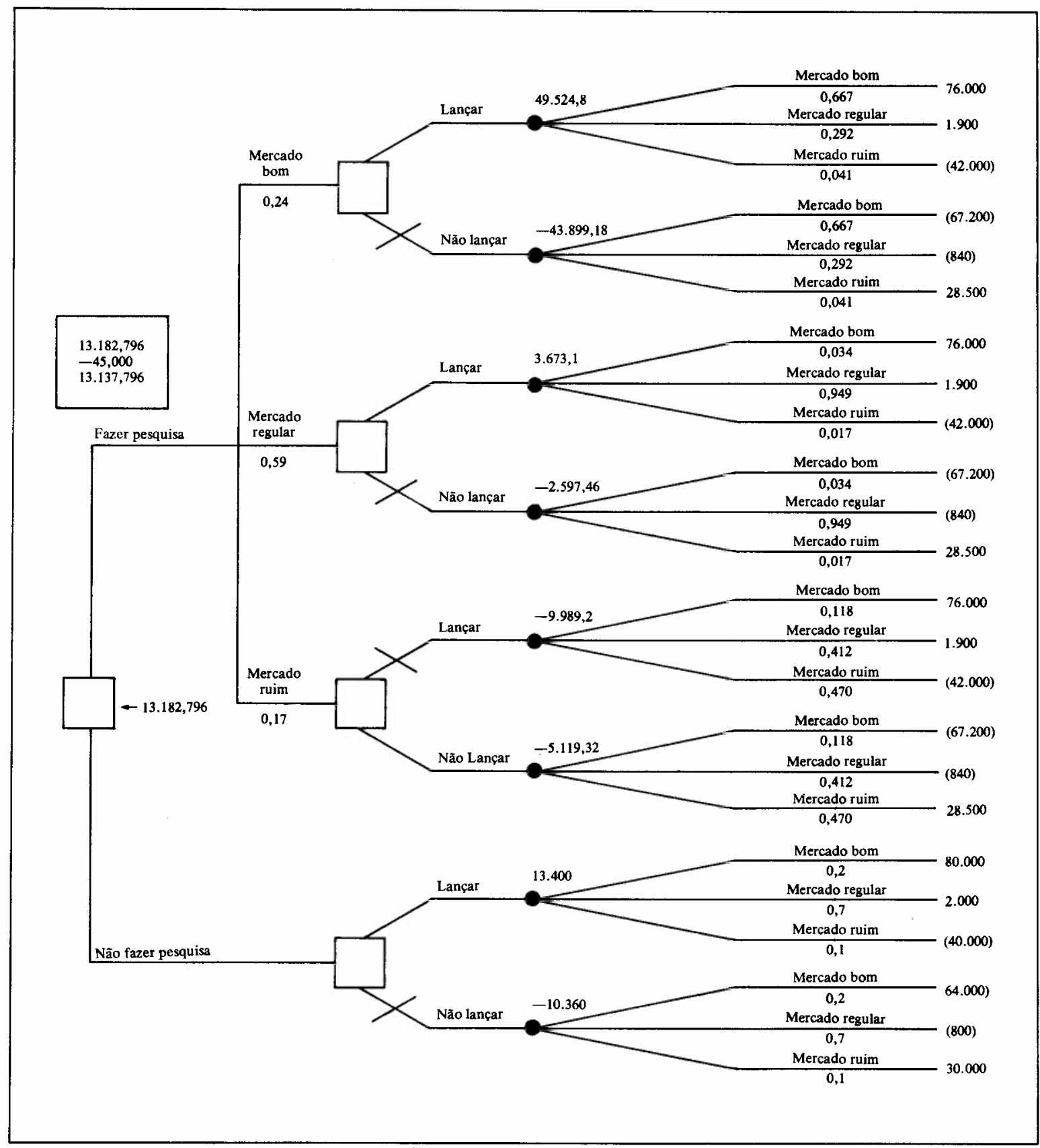

Valor Esperado da Informação Imperfeita = Valor Esperado da Decisão Ótima, dada a Opção por Colher Informação Amostral (DO/IA) - Valor Esperado da Decisão Ótima, dada a Inexistência de Informação Amostral $(\mathrm{DO} / \mathrm{SI})=\mathrm{Cr} \$ 13.182,796-\mathrm{Cr} \$ 13.400=-$ Cr $\$ 217,204$ milhões.

A preferência do gerente de vendas por não realizar o estudo de mercado sugerido no plano de pesquisa A deve-se, essencialmente à natureza, limitações e confiabilidade do próprio projeto de pesquisa. Uma investigação conduzida junto a $30 \%$ dos revendedores poten- ciais do novo produto, selecionados por conveniência $e$ a coleta de opiniões de todos os clientes de apenas 10 pontos de vendas, também escolhidos de sorte a atender aos interesses do pesquisador e não às características da população pesquisada, não são do tipo que gera informações com a confiabilidade necessária para fundamentar decisões adequadas em clima de incerteza.

A figura 5 esquematiza o processo decisório relacionado com as alternativas de não fazer pesquisa e tomar uma decisão terminal, ou realizar o estudo de mercado de acordo com o plano B e, então, tomar uma decisão conforme o resultado indicado pela pesquisa. 
São estas as ações sugeridas pelo esquema retratado na figura 5:

1. Se a conclusão do estudo fosse favorável à ocorrência de um mercado bom, a preferência do gerente de vendas deveria ser pela decisão de lançar o novo produto, cujo ganho marginal esperado seria de Cr\$58.286,20 milhões, contra uma perda de oportunidade esperada de Cr\$57.203,52, caso a escolha recaísse em não lançar o produto. A probabilidade deste evento é de $22 \%$.
2. Caso o laudo da pesquisa indicasse um mercadc regular, a opção ainda seria por lançar o novo produto. Olucro adicional esperado desta decisão seria Cr\$2.624 milhões, em contraste com a perda de oportunidade esperada Cr\$1.783,40 milhões, na eventualidade de que a escolha surgisse o não-lançamento do produto. A plausibilidade deste evento é de $64,5 \%$.

3. Na hopótese de que o achado da pesquisa apontasse para um mercado ruim, a decisão ótima seria a de

Figura 5

Análise de decisão com disponibilidade de informação de pesquisa - Plano B

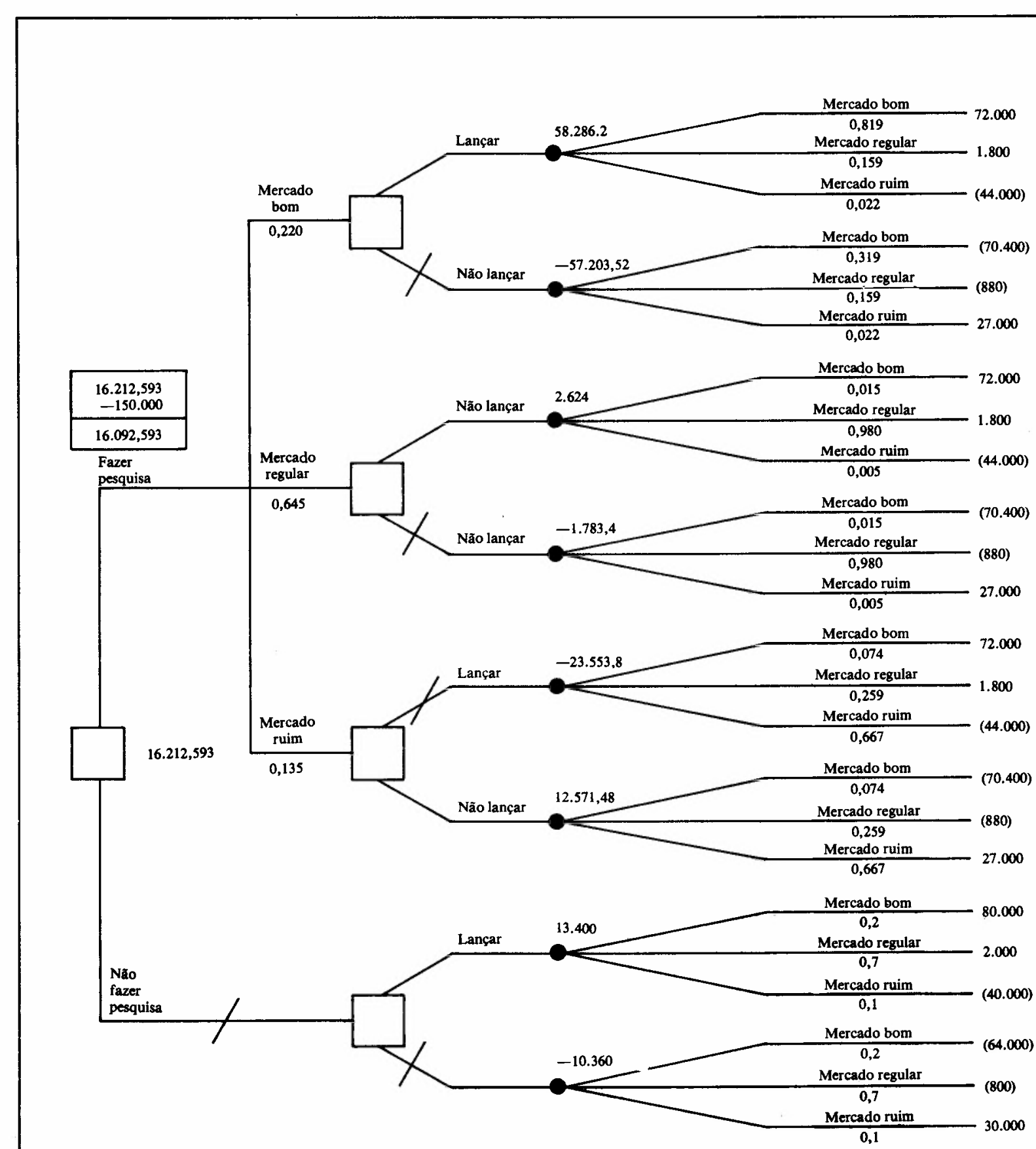


privilegiar o não-lançamento do produto, cujo ganho marginal esperado seria de $\mathrm{Cr} \$ 12.571,48$ milhões, comparado com o prejuizo esperado de $\mathrm{Cr} \$ 23.553 .80 \mathrm{mi}$ lhões, se fosse eleita a altenativa de lançar o novo produto. Este resultado sucederia com uma probabilidade de $13,5 \%$.

A decisão de realizar o plano de pesquisa $B$ e, posteriormente, tomar uma decisão resultaria num ganho marginal esperado de Cr\$16.212,593 milhões, contra Cr\$13.400 milhões, decorrentes da opção de não fazer pesquisa e lançar o novo produto, baseado apenas na crença do gerente de vendas relativamente às probabilidades de ocorrência dos diversos estados incertos da natureza.

$O$ valor esperado da informação amostral do plano de pesquisa $B$ é dado por:

Cr $\$ 16.212,593-\mathrm{Cr} \$ 13.400=\mathrm{Cr} \$ 2.812,593$ milhões. Como o custo orçado para o projeto de pesquisa é de apenas $\mathrm{Cr} \$ 150$ milhões, o gerente de vendas agiria corretamente se contratasse esse estudo de mercado e tomasse a melhor decisão para cada resultado indicado pela investigação.

A diferença substancial entre os valores esperados da informação amostral do plano de pesquisa $B$ e do plano de pesquisa A (Cr\$3.029,797 milhões) resulta, fundamentalmente, das diferenças de qualidade do projeto e de confiabilidade dos resultados proporcionados pelos dois tipos de estudo de mercado. No caso do plano $B$, o ganho líquido esperado da informação amostral é dado por $\mathrm{Cr} \$ 2.812,593-\mathrm{Cr} \$ 150=\mathrm{Cr} \$ 2.662,593 \mathrm{mi}-$ lhões. Se o plano de pesquisa $A$ for selecionado, o ganho líquido esperado da informação amostral será Cr\$217.204 - Cr\$45 = - Cr\$262.204 milhões. Este resultado salienta a conveniência de se avaliar vários projetos de pesquisa não apenas por seus custos orçados, mas principalmente pela capacidade de cada estudo de mercado prover, com a confiabilidade desejada, as informações imprescindiveis ao processo de tomada de decisão em clima de incerteza.

\section{COMENTÁRIOS FINAIS}

Este artigo apresentou uma abordagem estruturada com vistas a medir o valor de uma previsão em situações específicas de decisão. As técnicas empregadas foram análise de decisão e inferência bayesiana. No primeiro problema estudado, a decisão de aumentar as instalações produtivas da fábrica foi a opção preferida pelo tomador de decisão. No segundo problema analisado, a decisão ótima no estudo prévio da questão favoreceu olançamento do novo produto. A decisão de fazer pesquisa foi preterida no caso do plano de pesquisa A e preferida no plano de pesquisa B. Procurou-se demonstrar como um sistema de informações para apoio a decisões pode ser ampliado em diversos estágios, e como os segmentos desagregados de um problema podem ser recombinados em questões mais amplas.

Destacou-se a análise de decisão como um processo de melhoria progressiva, em que as estimativas sub- jetivas do tomador de decisão sẫo aceitáveis como pontos de partida para análise do problema.

O procedimento adotado neste artigo pode ser resumido nas seguintes etapas:

1. Desenvolver a lógica da situação inicial do problema a ser solucionado. Identificar os estados incertos da natureza, estipular as probabilidades subjetivas de ocorrência desses eventos, definir os cursos de ação alternativos e atribuir resultados terminais condicionados à escola dessas ações.

2. Tomar uma decisão prévia com base na informação existente.

3. Calcular os limites do valor esperado marginal da informação perfeita, a fim de determinar o valor máximo que seria possível pagar por informação adicional destinada a diminuir a incerteza.

4. Fazer uma análise pré-posterior das fontes disponiveis de informação adicional, com a finalidade de definir a escolha e a amplitude de investimentos incrementais que objetivem reduzir a incerteza.

5. Revistar as probabilidades e os valores esperados dos resultados provenientes da coleta de informação complementar.

6. Realizar estudos de sensibilidade para investigar a influência de níveis individuais de incerteza sobre as seleções de estratégias.

7. Repetir as etapas 4 e 6 até que os valores esperados das estratégias ótimas não possam mais ser melhorados com os recursos disponíveis da empresa.

8. Elaborar uma matriz das estratégias disponíveis, em que sejam identificados todos os resultados amostrais possíveis, o elenco das estratégias consideradas pelo tomador de decisão e os resultados terminais definidos.

9. Determinar o tamanho ótimo da amostra a ser empregada na coleta de informação adicional.

10. Escolher o curso ótimo de ação, implantar a estratégia eleita, calcular as probabilidades posteriores dos eventos incertos e aferir novamente o valor esperado da informação adicional.

\section{ANEXO 1}

Teorema de Bayes para variáveis aleatórias discretas

Suponha-se que $\mathrm{x}_{\mathrm{j}}, \mathrm{j}=1, \ldots \ldots . ., \mathrm{J}$ representem os $\mathrm{J}$ possiveis valores de uma variável aletória $X$, e que $B$ seja um valor possível de uma segunda variável aleatória, Y. O teorema ou regra de Bayes, atribuido ao matemático in- 
glês e pastor da Igreja Presbiteriana Thomas Bayes, assume a forma seguinte:

$$
P\left(X=x_{j} / Y=B\right)=\frac{P\left(Y=B / X=x_{j}\right) P\left(X=x_{j}\right)}{\sum_{j=1}^{\sum} P\left(Y=B / X=x_{j}\right) P\left(X=x_{j}\right)}
$$

O conjunto das probabilidades $\mathrm{P}\left(\mathrm{X}=\mathrm{xj}_{\mathrm{j}} / \mathrm{Y}=\mathrm{B}\right)$, para $\mathrm{j}=1, \ldots . . . . \mathrm{J}$, correspondem à distribuição condicional da variável $X$, dado que a variável aleatória $Y$ assume o valor B. Por conseguinte, o teorema de Bayes pode ser empregado para determinar a distribuição condicional de uma variável aleatória discreta.

O teorema de Bayes permite revisar as probabilidades relativas a um parâmetro $\mathrm{W}$ com base em informação amostral nova, que pode ser resumida pela estatística amostral Y.

O teorema de Bayes para variáveis aletórias contínuas tem esta expre``ão:

$$
f(W / y)=\frac{f(W) f(j / W)}{\int f(W) f(y / W) d W}
$$

em que:

$\mathrm{f}(\mathrm{W} / \mathrm{y})$ é a função de verossimilhança de $\mathrm{W}$, condicionada à ocorrência de y;

$f(W)$ é a função de densidade marginal de $\mathrm{W}$ e $\mathrm{f}(\mathrm{y} / \mathrm{W})$ é a função de verossimilhança de $\mathrm{Y}$, condicionada à ocorrência de $\mathrm{W}$.

As funções de densidade $f(W / Y), f(W)$ e $f(y / W)$ representam a distribuição posterior, a distribuição prévia e a função de verossimilhança, respectivamente. ${ }_{11}$

1 Lilien, Gary L. \& Kotler, Philip. Marketing decision making - a model building approach. New York, Harper \& Row, 1983. p. 174.

${ }_{2}$ Raiffa, Howard. Decision analysis: introductory lectures on choices under uncertainty. Reading, Massachusetts, Addison-Wesley, 1970. p. 86.

${ }_{3}$ Alderson, Wroe \& Green, Paul E. Planning and problem solving in marketing. Homewood, Illinois, Richard D. Irwing, 1964. p. 110.

${ }_{4}$ Hamburg, Morris. Statistical analysis for decision making. New York, Harcourt, Brace \& World, 1970. p. 12.

${ }_{5}^{\text {Id. ibid. p. } 624 .}$

${ }_{6}$ Raiffa, Howard. op. cit. p. 28-30.

${ }_{7}$ Hamburg, Morris. op. cit. p. 692.

${ }_{8}$ Gross, Charles W. \& Peterson, Robin T. Business forecasting. Boston, Mass., Houghton Mifflin, 1976. p. 36-47.

9ld. ibid. p. 38.

${ }_{10}$ Hamburg, Morris. op. cit. p. 684-5.

${ }_{11}$ Hays, William L. \& Winkler, Robert L. Statistics: probability, inference, and decision. New York, Holt, Rinehart \& Winston, 1970. v. 1, p. 446-59.
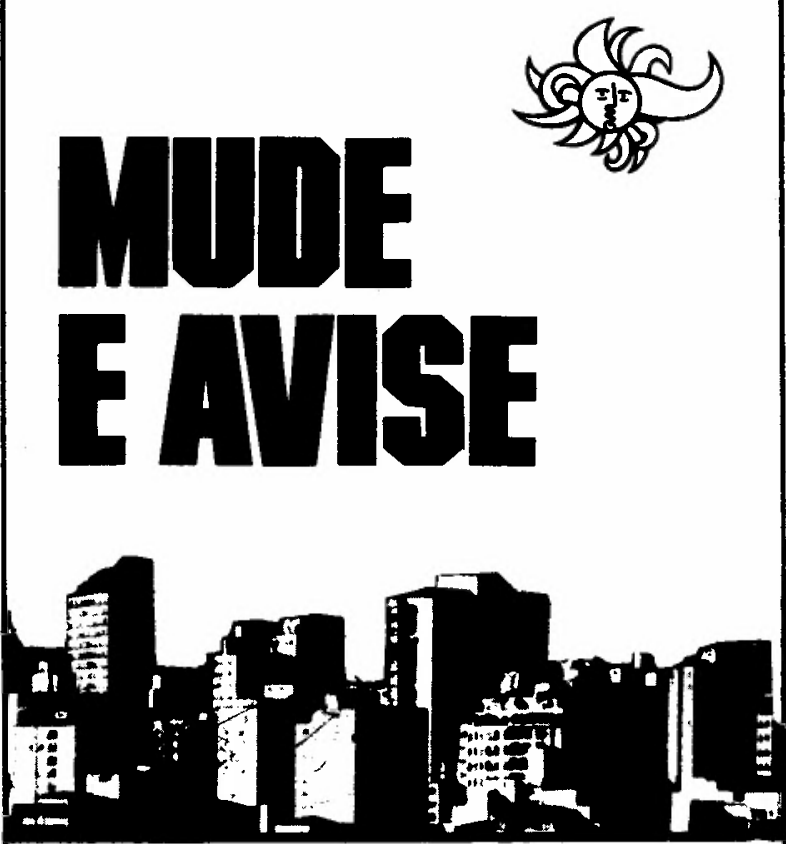

\section{ATENÇAO ASSINANTE}

Mudou-se? Avise-nos

Aproveite o cartão abaixo para comunicar sua mudança de endereço. Assim você evita o atraso no recebimento de sua revista.

Por gentileza, mencione o endereço antigo para facilitar nossos serviços.

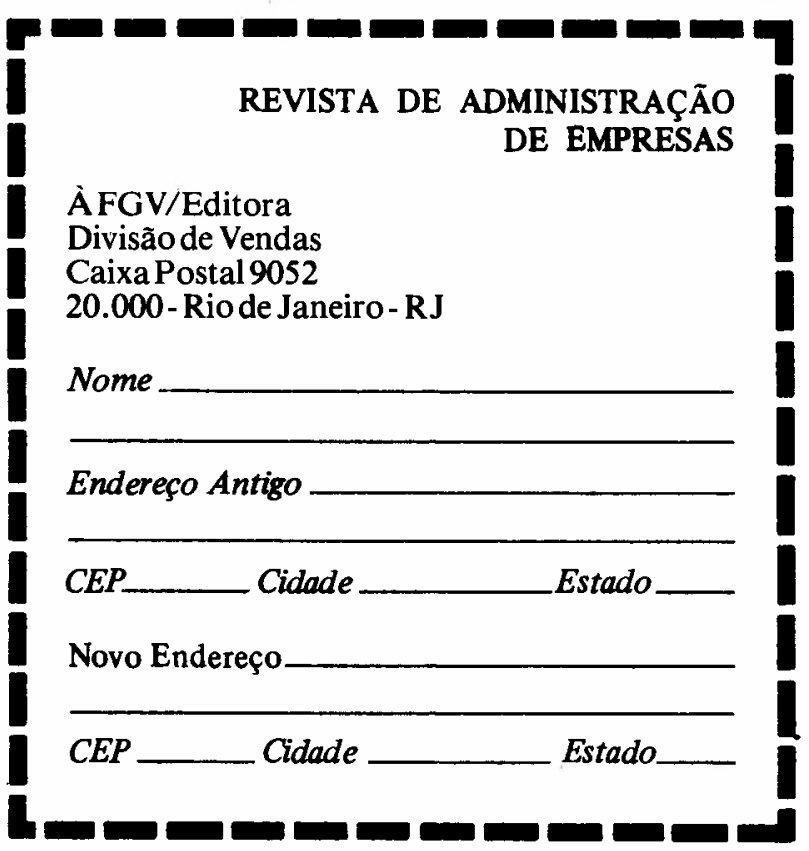

Revista de Administração de Empresas 